\title{
A Quantum Chemical Approach to the Influence of Platinum Surface Structure on the Oxygen Electroreduction Reaction
}

\author{
C. F. Zinola and A. J. Arvia* \\ Instituto de Investigaciones Fisicoquímicas Teóricas y Aplicadas (INIFTA), Universidad Nacional de La Plata, \\ Sucursal 4, Casilla de Correo 16, (1900) La Plata, Argentina
}

\author{
G. L. Estiu and E. A. Castro \\ Programa de Quimica Inorgánica (QUINOR), Universidad Nacional de La Plata, Casilla de Correo 962. \\ (1900) La Plata, Argentina \\ Received: January 21, 1994; In Final Form: May 2, $1994^{\circ}$
}

\begin{abstract}
The $\mathrm{O}_{2}$ electroreduction reaction (OERR) on $\mathrm{Pt}$ behaves as a structure sensitive reaction whose peroxo intermediates are formed in a greater extent on $\mathrm{Pt}(100)$ than on $\mathrm{Pt}(111)$ surfaces. A semiempirical quantum chemistry interpretation of this behavior is attempted on the basis of the study of $[\mathrm{Pt}]_{N} \mathrm{O}_{2} \mathrm{OH}$ systems, where $N$, the number of atoms in the Pt cluster, equals 18 and 25. Calculations indicate that dissociative $\mathrm{O}_{2}$ electroadsorption on $\mathrm{Pt}(111)$ and molecular $\mathrm{O}_{2}$ on $\mathrm{Pt}(100)$ are favored. As a result of the interactions of $\mathrm{O}_{2}$ and $\mathrm{OH}$ in adjacent positions, hydroperoxide intermediates are formed on $\mathrm{Pt}(100)$ leading to the possibility of having $\mathrm{H}_{2} \mathrm{O}_{2}$ as product from the OERR.
\end{abstract}

\section{Introduction}

The molecular oxygen electroreduction reaction (OERR) on $P t$ in acid solutions is one of the most relevant electrochemical reactions. ${ }^{1-3}$ It has been interpreted by a complex mechanism involving first the adsorption of molecular $\mathrm{O}_{2}$, followed by a charge-transfer step and desorption of electroreduced adsorbates, finally leading to $\mathrm{H}_{2} \mathrm{O}$ as the main product, and to $\mathrm{H}_{2} \mathrm{O}_{2}$ as minor product. ${ }^{4-6}$

Recent OERR kinetic data have shown different current density vs electrode potential relationships, depending on the topography of the Pt electrode in both acid ${ }^{7,8}$ and alkaline solutions. ${ }^{9}$ To account for these results, ${ }^{6,10-12}$ a more adequate interpretation of the OERR kinetics can be given by considering that there is a competition between the four-electron electroreduction to $\mathrm{H}_{2} \mathrm{O}$ and the two-electron electroreduction to $\mathrm{H}_{2} \mathrm{O}_{2}$, which can further decompose to $\mathrm{H}_{2} \mathrm{O}$. The relative contribution of each reaction depends on the Pt surface crystallography, the applied potential, and the nature and concentration of anions in the solution..$^{13,14}$ The value of $\theta_{0}$, the stationary $\mathrm{Pt}$ surface coverage by $O$-containing adsorbates in $\mathrm{O}_{2}$-saturated solution, changes almost linearly with the applied potential for all Pt surfaces. ${ }^{7}$ However, values of $\theta_{0}$ are greater for $\mathrm{Pt}(100)$ than for $\mathrm{Pt}(111)$ and polycrystalline (pc) $\mathrm{Pt}$, implying for the former an additional contribution to $\theta_{0}$ from other oxygenated adsorbed species.

The formation of $\mathrm{H}_{2} \mathrm{O}_{2}$ in the course of the OERR in aqueous solutions was almost twice as much for $\mathrm{Pt}(100)$ than for $\mathrm{Pt}(111)$ and pc Pt electrodes. ${ }^{7}$ The difference indicates either a more strongly adsorbed peroxide species or a faster $\mathrm{H}_{2} \mathrm{O}_{2}$ decomposition on $\mathrm{Pt}(111)$ and $\mathrm{pc} \mathrm{Pt}$ surfaces. Furthermore, the higher contribution of peroxo intermediates to the OERR on $\operatorname{Pt}(100)$ can explain the greater $\theta_{0}$ values found in $\mathrm{O}_{2}$-saturated acid solutions. ${ }^{7}$

The difference in the electronic characteristics of adsorption sites, resulting from the different crystallographic structures, leads to a topology dependence of the heterogeneous catalytic reaction kinetics. It has recently been found for the OERR on faceted 7,9 and single crysta $1^{8}$ Pt electrodes that there is a structure sensitivity in both acid and alkaline media, with a larger relative contribution of the two-electron reaction pathway on $\mathrm{Pt}(100)$ than on $\mathrm{Pt}(111)$

- Abstract published in Advance ACS Abstracts, June 15, 1994. and $\mathrm{pc} \mathrm{Pt}$. There facts were assigned to different interactions between $\mathrm{O}_{2}$ and the reaction intermediates with $\mathrm{Pt}(100)$ and $\mathrm{Pt}$. (111) surface structures.

Both experimental gas-phase ${ }^{15-18}$ and theoretical ${ }^{19-24}$ studies have shown different characteristics of $\mathrm{O}_{2}$ adsorption on Me(100) and $\mathrm{Me}(111)$ surfaces ( $\mathrm{Me}=$ transition metal). Thus, adsorbate configurations, resulting from molecular $\mathrm{O}_{2}$ adsorption on $\mathrm{Pt}(100)(5 \times 20)$ surfaces, depend on the degree of reconstruction of the Pt surface, as it can be inferred from thermal desorption spectroscopy (TDS) and X-ray photoemission measurements. ${ }^{25}$ Activation energies of ca. $0.4 \mathrm{eV}$ were found by molecular beam studies ${ }^{15}$ for the dissociative adsorption of $\mathrm{O}_{2}$ on $\mathrm{Pt}(100)$ with an enhancement of the sticking probability and no change on the threshold dissociation energy between 300 and 600 K.

Otherwise, on $\mathrm{Pt}(111)$, molecular $\mathrm{O}_{2}$ only predominates with respect to the $\mathrm{O}$ adatom, at temperatures below $120 \mathrm{~K} .{ }^{26}$ Electron energy loss spectroscopy (EELS) data show a primary vibrational mode at $870 \mathrm{~cm}^{-1}$, which is characteristic of peroxo-type species.26,27 According to near edge X-ray adsorption fine structure studies (NEXAFS), ${ }^{28-31}$ molecular $\mathrm{O}_{2}$ lies with the intermolecular axis parallel to the metal surface, in agreement with EELS detection of peroxo species. Likewise, $O$ adatoms predominant at temperatures higher than $170 \mathrm{~K}$, since a single vibrational mode at $490 \mathrm{~cm}^{-1}$, attributed to the O-Pt stretching frequency, is detected. ${ }^{26,32}$ Hence, the different behavior of the $\mathrm{O}_{2}$ (gas)/Pt(111) and $\mathrm{O}_{2}$ (gas) $/ \mathrm{Pt}(100)$ systems provides a first indication of different surface structure $\mathrm{O}_{2}-\mathrm{Pt}$ interactions which, in principle, could be reflected to some extent in the OERR on different $\mathrm{Pt}$ substrates.

Theoretical calculations are mainly related to lower-atomicnumber transition metals. 19-21,23,24 To our knowledge, no previous theoretical study of the $\mathrm{Pt}_{N} \mathrm{O}_{2}$ system has involved either the optimization of the adsorbate structure or the influence of the applied potential.

In this paper, the interaction of an $\mathrm{O}_{2}$ molecule with $\mathrm{Pt}(100)$ and $\mathrm{Pt}(111)$ cluster surfaces is analyzed at a molecular orbital level, as a first step to understand the influence of the electrode topology on the OERR mechanism. In this way, the selective generation of peroxo species on $\operatorname{Pt}(100)$ can be justified on the basis of the involved molecular orbital interactions and the different nature of the adsorbed intermediates on both surfaces. 


\section{Methodology}

2.1. Calculation Procedure. For the treatment of large polyatomic systems, computational chemistry deals, nowadays, with a compromise between an overall description of the entire system and a more detailed treatment of a properly selected part of it. This situation particularly applies to transition metal structures, which have to be drastically minimized for an adequate ab initio, local density functional, or even semiempirical calculation at a good correlation level. ${ }^{33-36}$ In contrast to this simplification of the system, the improvement of simpler methods, which are capable of handling the system as a whole, have regained acceptability. This is the case of the extended Hückel molecular orbital (EHMO) method developed by Hoffman, ${ }^{37}$ which was initially used for a reasonable description of the structural and electronic properties of systems at a frozen geometry. Improvements of this method are mainly related to the addition of twobody electrostatic correction terms. ${ }^{38-42}$ Accordingly, $E_{\mathrm{T}}$, the total energy of the system, is calculated from the contribution of two terms:

$$
\begin{gathered}
E_{\mathrm{T}}=\Delta E_{\mathrm{EHMO}}+E_{\text {rep }} \\
\Delta E_{\text {EHMO }}=E_{\text {EHMO }}-\sum_{\mu} b_{\mu}{ }^{\circ} E_{\mu}{ }^{\circ}
\end{gathered}
$$

where $\Delta E_{\mathrm{EHMO}}$ is the EHMO binding energy, calculated as the difference between $E_{\mathrm{EHMO}}$, the noncorrected EHMO total energy and the summation of the monoelectronic terms; $b_{\mu}{ }^{\circ}$ and $E_{\mu}{ }^{\circ}$ are the occupation number and the valence state ionization potential (VSIP) of the $\mu$ th atomic orbital. The correction implies the addition of $E_{\text {rep, }}$ the repulsion energy,

$$
E_{\text {rep }}=\sum_{\mathrm{A}} \sum_{\mathrm{B}<\mathrm{A}} E_{\mathrm{AB}}
$$

where $E_{\mathrm{AB}}$ is the electrostatic repulsion energy between atoms $\mathrm{A}$ and $\mathrm{B}$ separated by the distance $R_{\mathrm{AB}} . E_{\text {rep }}$ is a pairwise additive term which can be either explicitly calculated for a given pair of atoms $38,39,42$ or determined from binding energy differences when inner orbitals are either considered or neglected. 40,41

Calzaferri et al..$^{42-46}$ have reformulated the EHMO method by including the following two main modifications.

i. A repulsion energy that explicitly considers both atoms of a given pair,

$$
E_{\mathrm{AB}}=\frac{Z_{\mathrm{A}} Z_{\mathrm{B}}}{R_{\mathrm{AB}}}-1 / 2\left[Z_{\mathrm{A}} \int \frac{\rho_{\mathrm{B}}(\bar{r})}{\left|\bar{R}_{\mathrm{A}}-\bar{r}\right|} \mathrm{d} \bar{F}+Z_{\mathrm{B}} \int \frac{\rho_{\mathrm{A}}(\bar{r})}{\left|\bar{R}_{\mathrm{B}}-\bar{r}\right|} \mathrm{d} \bar{r}\right]
$$

where $Z_{l}, \bar{R}_{i}$ and $\rho_{i}$ are the nuclear charge, position, and electron density of atom $i,(i=\mathrm{A}, \mathrm{B})$, where atom $\mathrm{B}$ is more electronegative than atom $A$. The second right-hand side term in eq 4 is the arithmetic mean of $\mathbf{A}-\mathbf{B}$ and $\mathbf{B}-\mathbf{A}$ attractive interaction energies.

ii. A distance-dependent exponential factor that modifies the off-diagonal EHMO matrix elements according to

$$
H_{\mu \nu}^{\mathrm{AB}}=\frac{1}{2} K_{\mathrm{AB}}\left(H_{\mu \mu}+H_{\nu \nu}\right) S_{\mu \nu}
$$

where $K_{\mathrm{AB}}$ and $\delta$ are adjustable parameters related by the expression

$$
K_{\mathrm{AB}}=1+\kappa \exp \left[-\delta\left(R_{\mathrm{AB}}-d_{0}\right)\right]
$$

$K_{\mathrm{AB}}$ is the EHMO- $K$ parameter used in the off-diagonal Hamiltonian matrix elements, $H_{\mu \nu}^{\mathrm{AB}}, \mu$ and $\nu$ being the $\mu$ th and the $\nu$ th orbitals of atoms $A$ and $B$, respectively. $d_{0}$ is the sum of the atomic radii of $\mathrm{A}$ and $\mathrm{B}$. $K_{\mathrm{AB}}$ and $\delta$ are empirical parameters,
TABLE 1: Optimized Parameters from EHMO Calculations

\begin{tabular}{cccccc}
\hline orbital & VSIP $/ \mathrm{eV}$ & $\zeta_{1}{ }^{b}$ & $\zeta_{2}{ }^{b}$ & $c_{1}{ }^{c}$ & $c_{2}{ }^{c}$ \\
\hline Pt 5d & -12.83 & 4.0950 & 1.8600 & 0.7980 & 0.3520 \\
Pt 6s & -9.32 & 1.9830 & & & \\
Pt 6p & -5.72 & 1.3440 & & & \\
O 2s & -27.96 & 2.5640 & & & \\
O 2p & -12.16 & 2.2640 & & & \\
H 1s & -13.30 & 1.3000 & & &
\end{tabular}

a VSIP $\equiv$ valence state ionization potential. ${ }^{b} \zeta_{1,2} \equiv$ exponents of the base generating functions. ${ }^{c} c_{1,2} \equiv$ coefficients of the double $\zeta \mathrm{Pt} d$ orbitals.

such as $1.4 \leq(1+\kappa) \leq 2.5$ and $0.0 \leq \delta \leq 0.1 \mathrm{~nm}^{-1}$. The other energy matrix elements are kept as given by the conventional EHMO methodology, i.e.

$$
H_{\mu \mu}^{\mathrm{AA}}=-(\mathrm{VSIP})_{\mu}^{\mathrm{A}} ; \quad H_{\mu \nu}^{\mathrm{AA}}=0
$$

It has been demonstrated that a careful parametrization of the reformulated EHMO method allows us to optimize the geometry of either simple $e^{42-46}$ or organometallic complex molecules ${ }^{43}$ at a level that can be compared with high-quality calculations.

The preceding calculation procedure was employed to analyze the interaction of a single $\mathrm{O}_{2}$ molecule with $\mathrm{Pt}(111)$ and $\mathrm{Pt}(100)$ cluster surfaces, including the influence of an applied electrical potential. Because of the complex nature of the electrochemical interface, which involves the solution constituents, adsorbates, and substrate, the interaction energy resulting from coadsorbed species was considered to find out whether $\mathrm{O}_{2}$ dissociation is favored and to envisage the stability of adsorbates and final products, which can be related to the OERR on different $\mathrm{Pt}$ electrode surfaces.

2.2. Calculation Details. Values of the VSIP in eq 5 are experimentally based, and valence orbitals are of the Slater form. The $\mathrm{O}_{2}$ molecule-Pt site interactions are represented as an adsorbed ensemble, which is characterized by its specific VSIP. The VSIP value, which defines the equilibrium potential of the system, i.e., the zero applied potential condition, results when the charge transfer at the equilibrium distance of each internuclear bond is close to that predicted for the adsorbed ensemble from the electronegativity difference, according to Pauling's ionicity relationship. ${ }^{53}$ VSIP values, adjusted in this way, are assembled in Table 1.

Following the previously described method, ${ }^{54}$ VSIP and Slater orbital exponents were taken from refs 46 and 54 for the substrate and the adsorbate, respectively. Values $\delta=0.035 \mathrm{~nm}^{-1}$ and $K_{\mathrm{AB}}$ $=1.75$ have been set in eq 6 . Results from different $K_{\mathrm{AB}}$ values $\left(1.5 \leq K_{\mathrm{AB}} \leq 2.0\right)$ have also been compared, and the $K_{\mathrm{AB}}$ that best describes bond lengths and adsorption energies in $\mathrm{Pt}_{5}$ testing clusters has been adopted. The VSIP adjustment to chargetransfer conditions was made for different $(K, \delta)$ pairs. The best set of $K, \delta$, VSIP, and Slater orbitals was finally chosen from the description of the adsorption interactions.

As a positive applied electric potential $(E)$ shifts downward the metal energy Fermi level and vice versa, changes in the electrode potential were simulated by either decreasing or increasing the absolute value of the metal VSIP from the reference equilibrium value, for negative or positive charging, respectively ${ }^{55,56}$ (Table 1). The $\Delta$ (VSIP)/ $\Delta E$ value was set equal to 1 , as there was no other clear experimental evidence which could justify a different choice.

High spin bulk superimposable bilayer $\mathrm{Pt}_{N}$ clusters, with the number of atoms $N=18$ and $N=25$ for $\operatorname{Pt}(100)$, and $N=18$ for Pt(111), (Figure 1), were used to model Pt surfaces. Clusters were geometrically built up, keeping the $\mathrm{Pt}-\mathrm{Pt}$ bond length, $r_{\mathrm{Pt}-\mathrm{Pt}}$, constant at $0.277 \mathrm{~nm}$. This figure, which has been used in previous calculations, ${ }^{55,56}$ agrees with the $\mathrm{Pt}-\mathrm{Pt}$ interatomic distance in bulk Pt. ${ }^{57}$ The open shell configuration of the $\mathrm{O}_{2}$ molecule $\left({ }^{3} \Sigma_{g}^{-}\right)$has been considered in the definition of the spin magnetic 


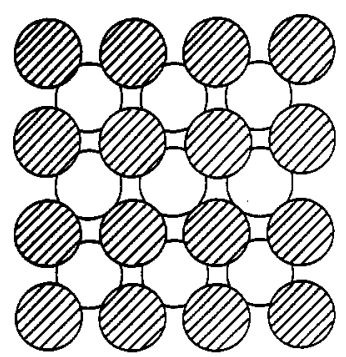

a

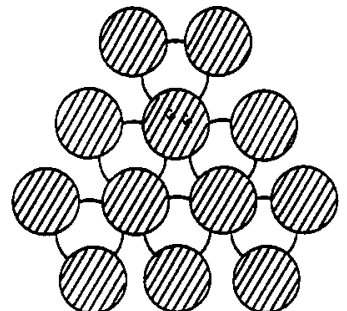

b

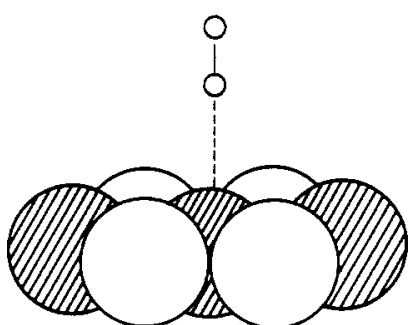

a



C

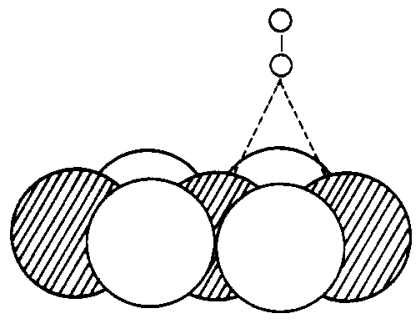

b

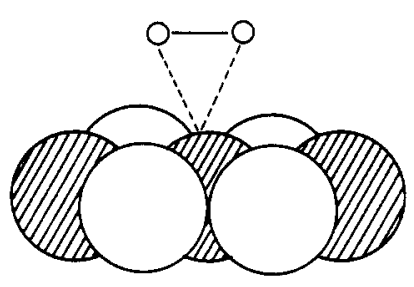

d Otherwise, either three or four $\mathrm{Pt}$ atoms may define the hollow coordination in $\mathrm{Pt}(111)$, depending on whether the fcc or the hcp local symmetry, i.e., the (3-1) or the (3-3) hollow site, respectively, is involved. The interaction of an $\mathrm{O}_{2}$ molecule with these sites defines several adsorption configurations (see section 3.1).

The interaction of a single $\mathrm{O}_{2}$ molecule with a $\mathrm{Pt}$ surface was initially considered, but the OERR in aqueous environments also involves $\mathrm{H}_{2} \mathrm{O}$ and other coadsorbed intermediates on the $\mathrm{Pt}$ surface. In the $0.60-1.00-\mathrm{V}$ (vs reversible hydrogen electrode) potential range, where $\mathrm{O}_{2}$ adsorption takes place, there is an important contribution of adsorbed $\mathrm{OH}$ species. Therefore, the stability of the adsorbed ensemble, constituted by $\mathrm{O}_{2}, \mathrm{OH}$, and Pt sites, was evaluated as a function of the applied potential. While the coordinates of the Pt atoms were kept frozen in the calculations, the $\mathrm{Pt}-\mathrm{O}, \mathrm{O}-\mathrm{O}$, and $\mathrm{O}-\mathrm{H}$ distances and angles were fully optimized to minimum energy.

\section{Results and Interpretation}

3.1. Interaction of a Single $\mathrm{O}_{2}$ Molecule with $\mathrm{Pt}(111)$ and Pt(100) Cluster Surfaces: The Most Likely Stable Configuration of the Adsorbed $\mathrm{Pt}_{\mathrm{N}} \mathrm{O}_{2}$ Ensemble. Because of the important role of $\mathrm{O}_{2}$ frontier orbitals $\left(\pi, \pi^{*}\right)$ in the interaction with the Pt surface, adsorption geometries with the $\mathrm{O}-\mathrm{O}$ interatomic bond parallel to the Pt surface plane are likely to occur. However, the "parallel" (side-on) and the "perpendicular" (end-on) configurations were compared. Among possible configurations, the most important ones are those which involve either the coordination of one 0 atom to a single surface site (1-fold, bridge and hollow coordination) (Figure $2 a-c$ ) or the simultaneous coordination of both $O$ atoms from $\mathrm{O}_{2}$ to a unique surface site (on-top side-on or bridge side-on configuration) (Figure 2d,e).

The geometry of each adsorbate configuration was fully optimized in bond distances and planar and dihedral angles, taking into account the orientation of the $\mathrm{O}-\mathrm{O}$ bond relative to the $\mathrm{Pt}-$ Pt bond in the lattice.

The geometrical characteristics and relative stabilities of each adsorbate structure are compared in Table 2. Binding energies, BE, were calculated as

$$
\mathrm{BE}=-\left(E_{\mathrm{T}, \mathrm{Pt}_{\mathrm{N}} \mathrm{O}_{2}}-E_{\mathrm{T}, \mathrm{Pt}_{N}}-E_{\mathrm{T}, \mathrm{O}_{2}}\right)
$$

where $E_{\mathrm{T}, \mathrm{Pt}_{\mathrm{N}} \mathrm{O}_{2}}, E_{\mathrm{T}, \mathrm{Pt}_{\mathrm{N}},}$ and $E_{\mathrm{T}, \mathrm{O}_{2}}$ are the total energy, of $\mathrm{Pt}_{N} \mathrm{O}_{2}$, $\mathrm{Pt}_{N}$, and $\mathrm{O}_{2}$, respectively, resulting from eq 1 . The $E_{\mathrm{T}, \mathrm{O}_{2}}$ value results from a full optimization of the ${ }^{3} \Sigma_{-}$configuration, which is known to be the most stable one. From these calculations, $\mathrm{ro-}_{\mathrm{O}}$, the equilibrium $\mathrm{O}-\mathrm{O}$ bond length in an isolated $\mathrm{O}_{2}$ molecule, $=0.133 \mathrm{~nm}$, a figure which is $6 \%$ greater than the experimental
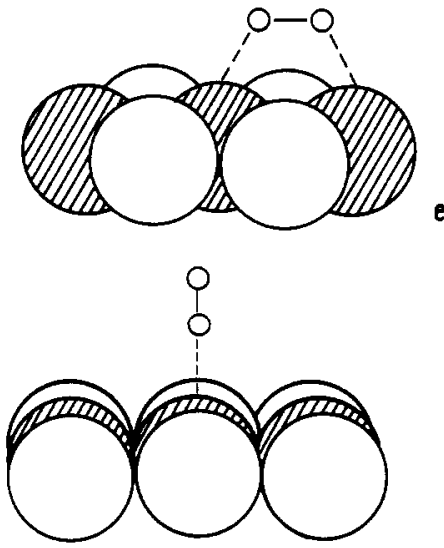

f
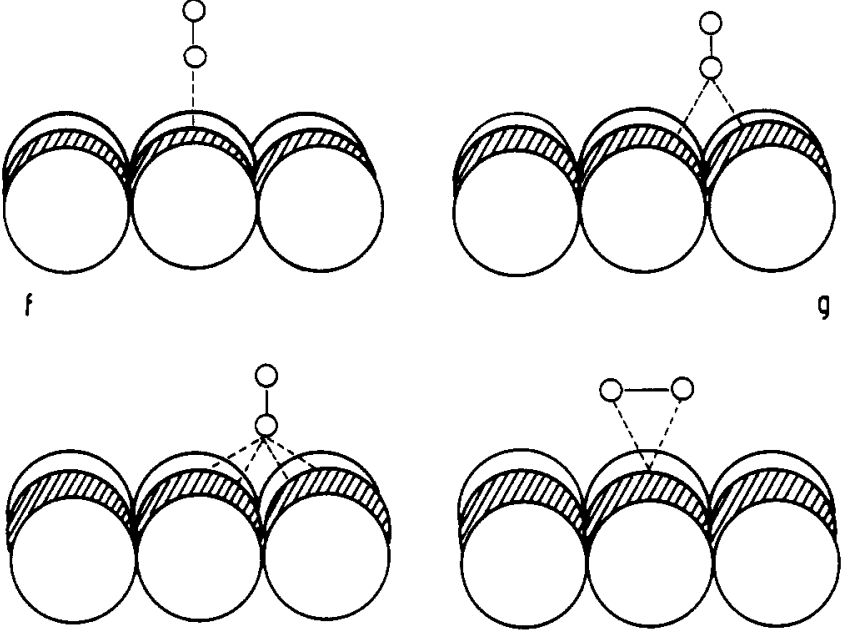

h

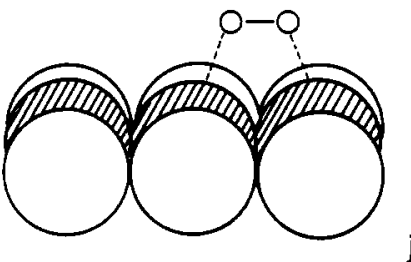

Figure 2. Different $\mathrm{Pt}_{\mathrm{N}} \mathrm{O}_{2}$ adsorption configurations on $\mathrm{Pt}(100)$ and Pt(111) surfaces: $(a, f)$ on-top end-on, $(b, g)$ bridge end-on, $(c, h)$ bridge side-on, $(d, i)$ on-top side-on, and $(e, j)$ hollow.

ro-o value, ${ }^{59,60}$ and a dissociation energy of $2.02 \mathrm{eV}$ was also calculated. The reproducibility of diatomic $\mathrm{O}_{2}$ experimental data was also considered for the parameter selection.

The optimization of the adsorbed ensemble geometries implies the simultaneous modification of $r_{0-0}$ and $r_{\mathrm{P}_{-}-}, \mathrm{O}-\mathrm{O}$ and $\mathrm{Pt}-\mathrm{O}$ bond lengths, respectively, $\mathrm{Pt}-\mathrm{O}-\mathrm{O}$ and $\mathrm{Pt}-\mathrm{Pt}-\mathrm{O}$ planar angles, and $\mathrm{Pt}-\mathrm{Pt}-\mathrm{O}-\mathrm{O}$ and $\mathrm{Pt}-\mathrm{Pt}-\mathrm{Pt}-\mathrm{O}$ dihedral angles. To establish 
TABLE 2: Molecular O, Binding Energies, BE, Repulsion Energies, RE, Optimized Pt-O and $\mathbf{O}-0$ Distances $\left(\boldsymbol{R}_{\mathrm{Pt}-0}\right.$ and $r_{0-0}$ ), and Perpendicular Distance from the 0 Atom Closer to the Plane of the Pt Surface $(h)$, for Different $[\mathrm{Pt}(111)]_{18} \mathrm{O}_{2}$ and $[\mathrm{Pt}(100)]_{18} \mathrm{O}_{2}$ Configurations at Zero Potentiale

\begin{tabular}{lrrrrr}
\hline & $\mathrm{BE}(\mathrm{eV})$ & $\mathrm{RE}(\mathrm{eV})$ & $r_{\mathrm{Pt}-\mathrm{O}}(\mathrm{nm})$ & $r_{\mathrm{O}-\mathrm{O}}(\mathrm{nm})$ & $h(\mathrm{~nm})$ \\
\hline $\mathrm{Pt}(111)$ & & & & & \\
on-top end-on & -1.9213 & 5.5997 & 0.189 & 0.120 & 0.189 \\
bridge end-on & -1.2655 & 5.5839 & 0.217 & 0.116 & 0.168 \\
bridge side-on & -2.5920 & 6.2410 & 0.185 & 0.138 & 0.171 \\
on-top side-on & -1.3225 & 7.9341 & 0.177 & 0.258 & 0.129 \\
hollow (3-1) & 0.9211 & 12.4382 & $0.167^{b}$ & 0.220 & -0.006 \\
hollow (3-3) & 2.2900 & 11.3150 & $0.167^{b}$ & 0.220 & -0.006 \\
Pt(100) & & & & & \\
on-top end-on & -2.3653 & 5.5459 & 0.185 & 0.120 & 0.185 \\
bridge end-on & -1.8283 & 4.8146 & 0.207 & 0.130 & 0.155 \\
bridge side-on & -4.0749 & 7.3146 & 0.180 & 0.119 & 0.161 \\
on-top side-on & -3.3177 & 8.5790 & 0.172 & 0.243 & 0.121 \\
hollow & 1.5971 & 7.9083 & $0.196^{b}$ & 0.218 & -0.019
\end{tabular}

a For the on-top (side-on) and hollow interactions, BE's correspond to the atomic final state (as can be derived from ro-o). No local minima for the molecular configuration were found. ${ }^{b}$ For the hollow configuration, $r_{P_{1}-0}$ refers to the distance between the deeper $O$ atom and the surface Pt plane.

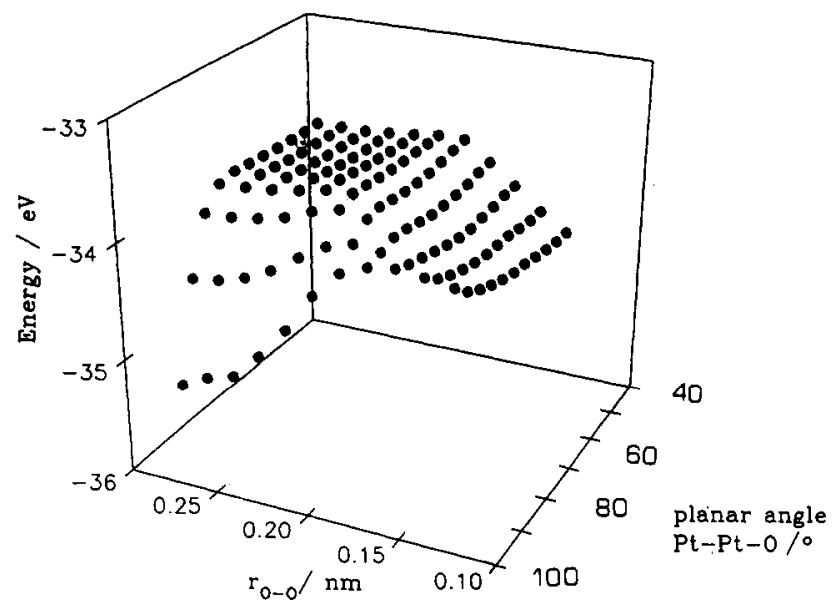

Figure 3. Potential energy hypersurface for the bridge side-on $\mathrm{O}_{2}$ adsorption configuration on $[\mathrm{Pt}(100)]_{18}$ at $0 \mathrm{eV}$.

whether molecular or dissociative $\mathrm{O}_{2}$ adsorption takes place, it is convenient to analyze the energy change with $r_{0-0}$ and $r_{P t-O}$, that is, through the potential energy hypersurface (Figure 3 ). This diagram was constructed for each $\mathrm{Pt}_{\mathrm{N}} \mathrm{O}_{2}$ adsorbate ensemble configuration on $\mathrm{Pt}(111)$ and $\mathrm{Pt}(100)$ clusters, with the simultaneous variations of $\mathrm{r}_{\mathrm{O}-\mathrm{O}}$ and the $\mathrm{Pt}-\mathrm{Pt}-\mathrm{O}$ planar angle (in fact $\left.r_{\mathrm{P} 1-0}\right)$. The most likely reaction pathway for the $\mathrm{O}_{2}$ dissociation was followed through the minimum energy path in the potential energy profile. For the bridge side-on configuration, the likely pathway for the dissociation process involves first the opening of the planar angle from $64^{\circ}$ to $80^{\circ}$, i.e., ro-o from 0.12 to $0.18 \mathrm{~nm}$, then a change in the Pt-O bond length from 0.18 to $0.165 \mathrm{~nm}$, and finally the perpendicular configuration of $\mathrm{O}$ atomic species is accomplished. Most of the changes in the potential energy values for the $\mathrm{O}_{2}$ dissociation are due to the elongation of the $\mathrm{O}-\mathrm{O}$ bond distance; therefore it is reasonable to admit only ro-o for the definition of the reaction coordinate of the potential energy diagram. For this purpose, $0.001 \mathrm{~nm}$ stepwise variations in $r_{0-0}$ were searched for minimum energy from the initial $r_{0-}=0.080$ $\mathrm{nm}$ value up to those at which $\mathrm{O}_{2}$ dissociation occurs. Then, for a fixed ro-o value, other coordinates were fully optimized (Table 2). Optimized geometries correspond to local minima in the energy vs ro-o plot. These minima do not necessarily imply that $\mathrm{O}_{2}$ dissociation is excluded (Figure 5a,b). As a better description of the potential energy curves for dissociation processes at distances larger than that of equilibrium, the extended Hückel binding energy, BE, can be corrected by means of either a self-consistent charge iteration ${ }^{44}$ or the addition of an electrostatic interaction term between the positive and negative species. ${ }^{61}$ The stability of the $\mathrm{Pt}_{N} \mathrm{O}_{2}$ ensemble can be determined from the energy barrier that has to be surmounted to go from molecular $\mathrm{O}_{2}$ to a single $\mathrm{O}$ atom coordinated adsorbate ensemble. According to data shown in Figure 5a,b, local minima in the energy vs ro-o plot are not clearly defined for some configurations, i.e., hollow adsorption on $\mathrm{Pt}(100)$ and bridge side-on adsorption on $\mathrm{Pt}(111)$. Nevertheless, in these cases, an inflection point in the energy vs $r_{0-0}$ data (unobservable in the energy scale used in the plot) allowed us to calculate the geometric properties of the adsorbates at that point (Table 2).

For the different adsorbate configurations, $\sigma$ and $\pi \mathrm{O}_{2}$ orbitals are involved, their relative weight depending on the specific geometry of the adsorption site.

For the linear on-top end-on coordination (Figure 2a,f) the interaction of the $\pi \mathrm{O}_{2}$ molecular orbital with the $\left(\mathrm{d}_{x z}, \mathrm{~d}_{y_{z}}\right) \mathrm{Pt}$ atomic orbital is more important than that of the $\sigma \mathrm{O}_{2}-\mathrm{d}_{z^{2}} \mathrm{Pt}$, the $z$ axis being perpendicular to the Pt surface (Figure $4 a, f$ ). The contribution of the $\pi^{*} \mathrm{O}_{2}$ molecular orbital to the stability of the $\mathrm{d}_{x y} \mathrm{Pt}$ atomic orbitals is negligible. The net interaction can be described as a charge transfer to the Pt surface which, being similar for both $\mathrm{Pt}(111)$ and $\mathrm{Pt}(100)$ (Table 3), reflects the local character of the linear bond.

Otherwise, bridge end-on coordination (Figure $2 \mathrm{~b}, \mathrm{~g}$ ) implies a greater stabilization of the $\sigma \mathrm{O}_{2}$ molecular orbital, through a bonding interaction with adjacent $\mathrm{Pt}$ atom $\mathrm{d}_{x^{2}-y^{2}}$ orbitals, rather than a $\pi$-type interaction (Figure $4 \mathrm{c}, \mathrm{g}$ ), which involves a coordination of $\pi$ orbitals from both $\mathrm{Pt}$ and $\mathrm{O}_{2}$. However, the more important $\pi$ interaction on $\mathrm{Pt}(100)$ than on $\mathrm{Pt}(111)$ appears to be responsible for the greater stability of the bridge end-on coordination geometry in $\mathrm{Pt}(100)$, and $\pi$ orbitals are not really hybridized for a further contribution to Pt-Pt bonding. In spite

TABLE 3: Net Charges $\left(q_{01}\right.$ and $\left.q_{02}\right)$ and $\sigma$ and $\pi$ Mulliken Populations in the $O$ Atoms $\left(M_{\sigma}\left(O_{1,2}\right)\right.$ and $\left.\mathbf{M P}_{\pi}\left(O_{1,2}\right)\right)$, for Different $[\mathrm{Pt}(111)]_{18} \mathrm{O}_{2}$ and $[\mathrm{Pt}(100)]_{18} \mathrm{O}_{2}$ Configurations, as Described in Table 2

\begin{tabular}{|c|c|c|c|c|c|c|}
\hline & $q_{01}(\mathrm{eu})$ & $\mathrm{MP}_{\sigma}\left(\mathrm{O}_{1}\right)$ & $M P_{\star}\left(O_{1}\right)$ & $q_{\mathrm{O} 2}(\mathrm{eu})$ & $\mathrm{MP}_{\sigma}\left(\mathrm{O}_{2}\right)$ & $\mathrm{MP}_{\pi}\left(\mathrm{O}_{2}\right)$ \\
\hline free $\mathrm{O}_{2}$ & 0 & 3.4737 & 2.5263 & 0 & 3.4737 & 2.5263 \\
\hline $\begin{array}{l}\text { Pt }(111) \\
\text { on-top end-on } \\
\text { bridge end-on } \\
\text { bridge side-on } \\
\text { on-top side-on } \\
\text { hollow (3-1) } \\
\text { hollow (3-3) }\end{array}$ & $\begin{array}{l}1.5323 \\
1.5741 \\
0.8598 \\
0.7686 \\
1.6933 \\
1.5551\end{array}$ & $\begin{array}{l}2.5353 \\
2.4733 \\
2.7251 \\
2.8708 \\
2.4457 \\
2.4704\end{array}$ & $\begin{array}{l}1.9322 \\
1.9525 \\
2.4150 \\
2.3604 \\
1.8609 \\
1.9743\end{array}$ & $\begin{array}{r}0.7742 \\
0.9274 \\
0.8598 \\
0.7686 \\
-0.2175 \\
-0.0626\end{array}$ & $\begin{array}{l}2.9175 \\
2.9070 \\
2.7251 \\
2.8708 \\
3.2850 \\
3.1238\end{array}$ & $\begin{array}{l}2.7050 \\
2.1654 \\
2.4150 \\
2.3604 \\
2.9324 \\
2.9387\end{array}$ \\
\hline $\begin{array}{l}\text { Pt(100) } \\
\text { on-top end-on } \\
\text { bridge end-on } \\
\text { bridge side-on } \\
\text { on-top side-on } \\
\text { hollow }\end{array}$ & $\begin{array}{l}1.5204 \\
1.4390 \\
1.1886 \\
0.6294 \\
1.6569\end{array}$ & $\begin{array}{l}2.5247 \\
2.5284 \\
2.6595 \\
2.8578 \\
2.5687\end{array}$ & $\begin{array}{l}1.9548 \\
2.0324 \\
2.1517 \\
2.5110 \\
1.7741\end{array}$ & $\begin{array}{r}0.7075 \\
0.5793 \\
1.1886 \\
0.6294 \\
-1.0843\end{array}$ & $\begin{array}{l}2.9203 \\
2.9562 \\
2.6595 \\
2.8578 \\
3.7322\end{array}$ & $\begin{array}{l}2.3720 \\
2.4643 \\
2.1517 \\
2.5110 \\
3.3520\end{array}$ \\
\hline
\end{tabular}




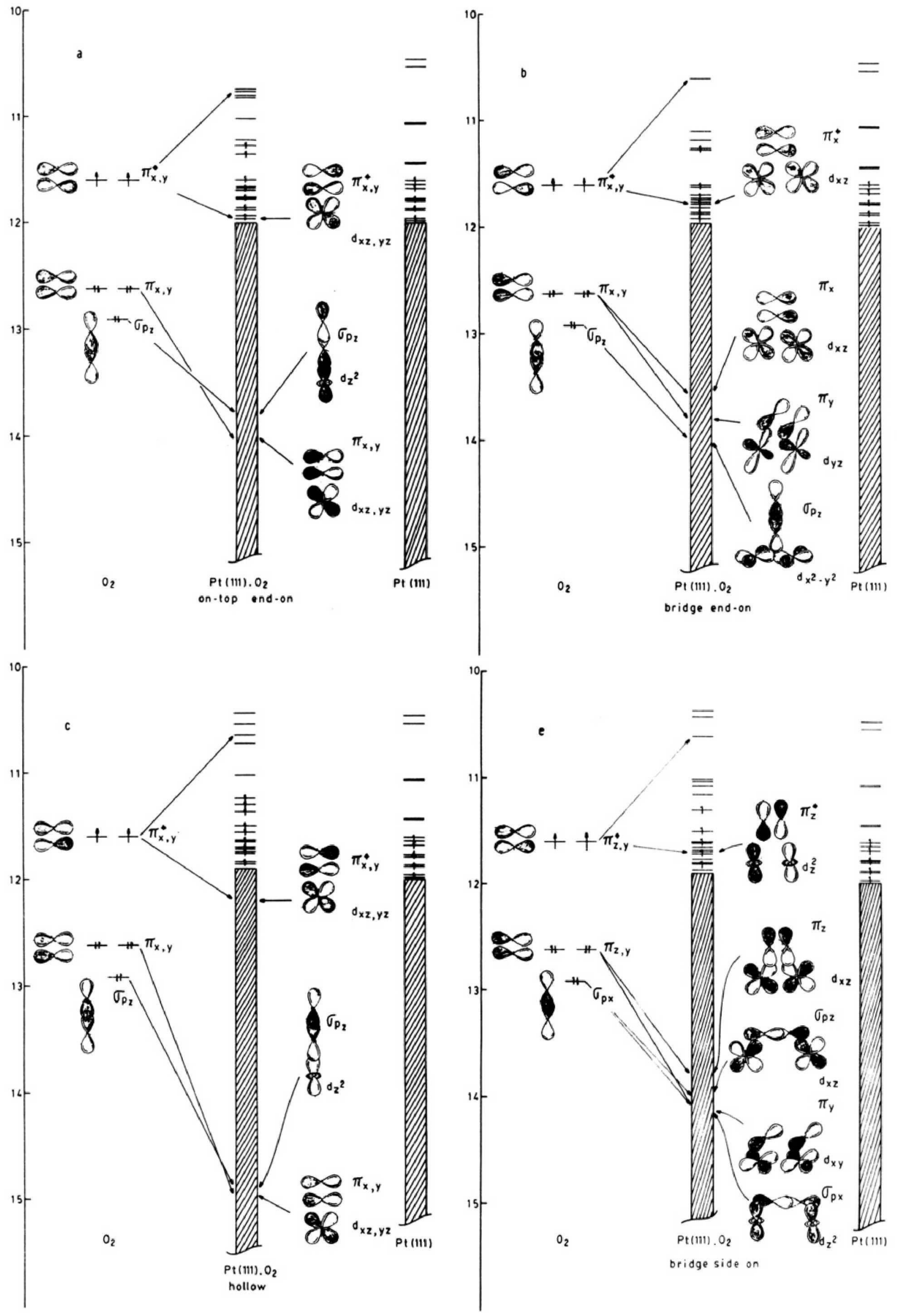


$\mathrm{O}_{2}$ Electroreduction on $\mathrm{Pt}$
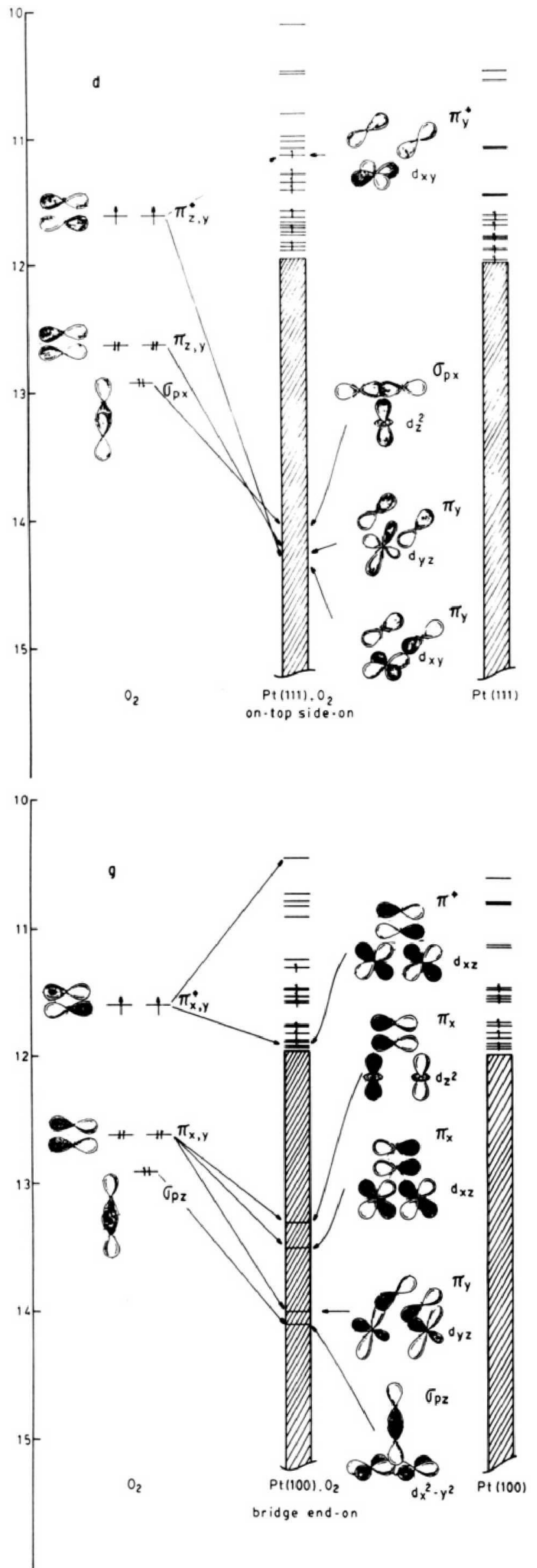

The Journal of Physical Chemistry, Vol. 98, No. 31, 1994

7571
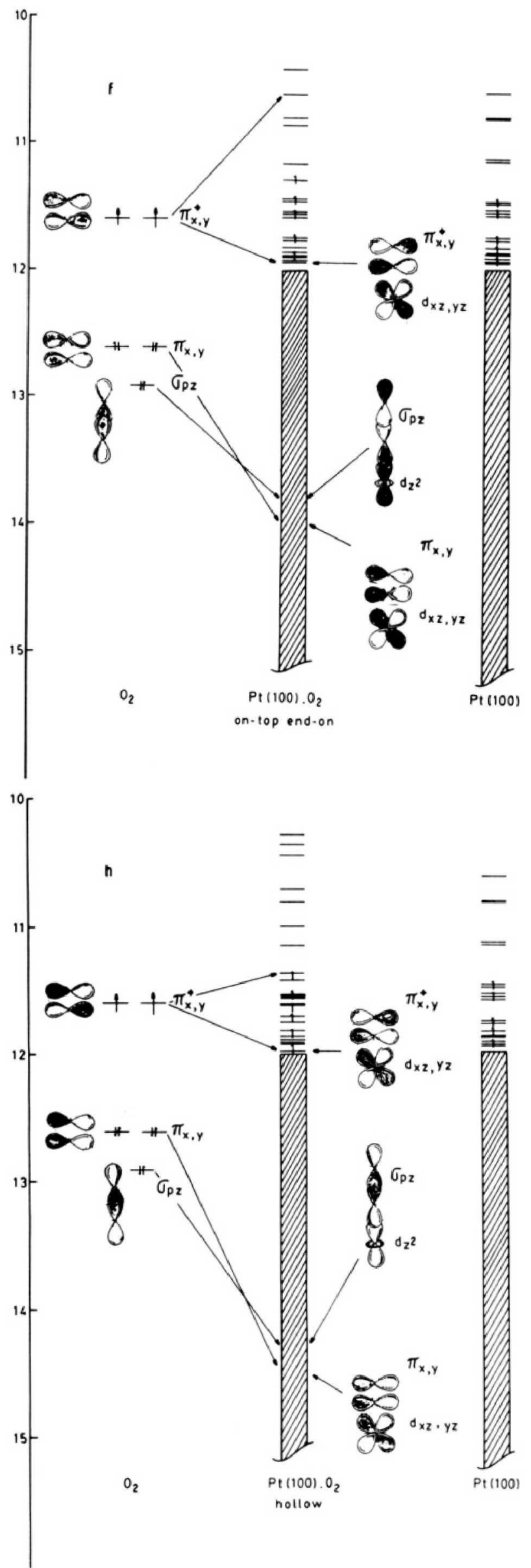

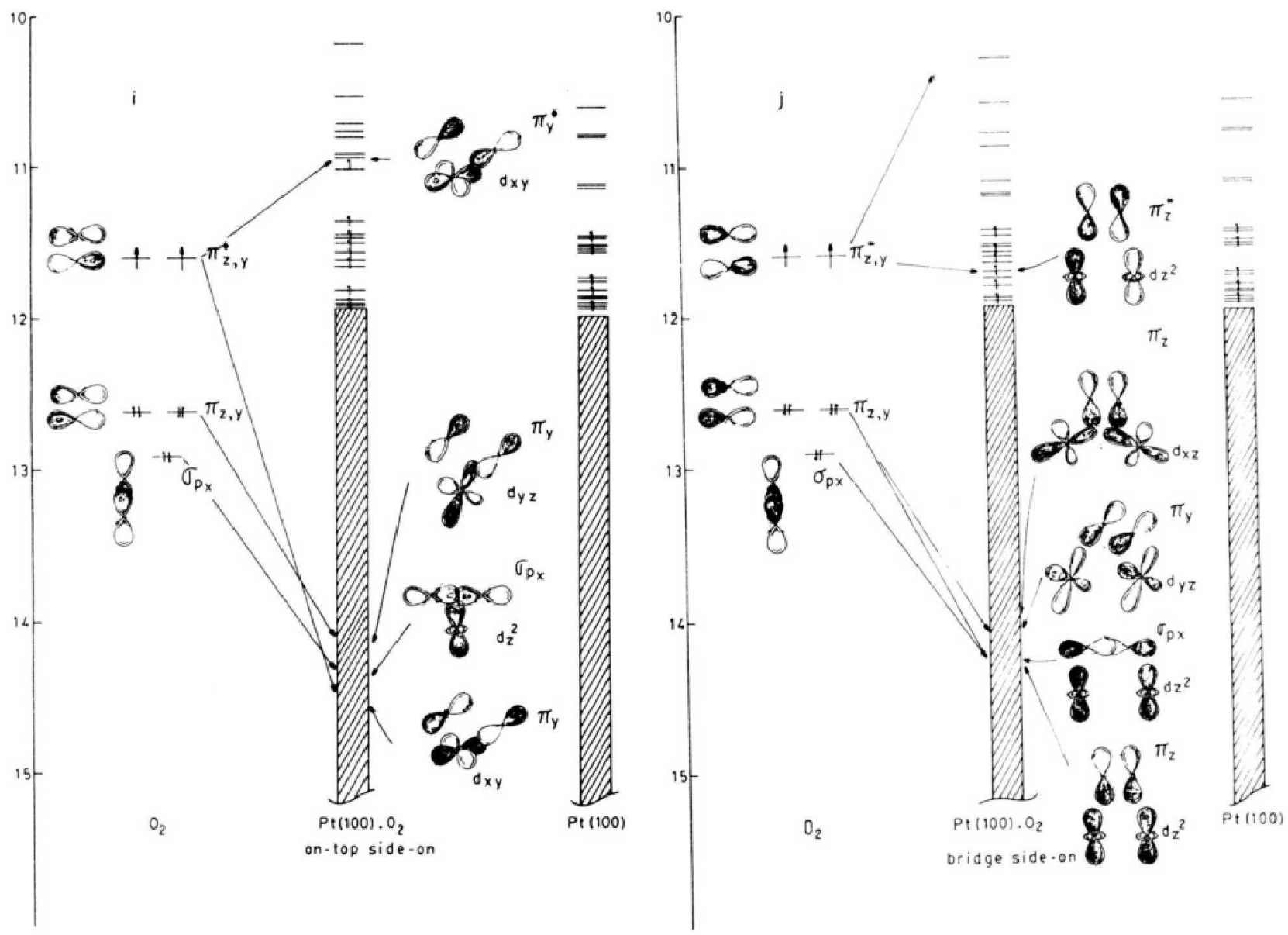

Figure 4. Molecular orbital interaction for different $[\mathrm{Pt}(100)]_{18} \mathrm{O}_{2}$ and $[\mathrm{Pt}(111)]_{18} \mathrm{O}_{2}$ adsorbate configurations, as depicted in Figure 2: (a,f) on-top end-on, $(b, g)$ bridge end-on, $(c, h)$ hollow, $(d, i)$ on-top side-on, and $(e, j)$ bridge side-on.

of the shorter $\mathrm{Pt}-\mathrm{O}$ bond length on $\mathrm{Pt}(100)$, the lower repulsion energy value (Table 2) is due to the fact that the electron density is lower in the less densely packed $\mathrm{Pt}(100)$ structure than in that of $\mathrm{Pt}(111)$. The lower repulsion energy value also contributes to the stability of bridge end-on coordinated adsorbate. Both $\sigma$ and $\pi$ interactions imply a charge transfer to $\mathrm{Pt}$, as can be inferred from the decrease in $\sigma$ and $\pi$ Mulliken populations in $\mathrm{O}$ atoms (Table 3). These populations were defined according to the $x$, $y$, and $z$ axis contributions to the $\pi$ and $\sigma$ orbitals. Unfortunately, no direct comparison of the $\sigma$ and $\pi$ relative Mulliken population values of $\mathrm{Pt}(111)$ and $\mathrm{Pt}(100)$ can be made because the equilibrium geometries to which the data belong are different for both substrates. The greater $\mathrm{O}-\mathrm{O}$ bond distance (Table 2 ) for the $\mathrm{O}_{2}$ molecule adsorbed on $\mathrm{Pt}(100)$ agrees with the larger $\pi$ orbital Mulliken population (Table 3), showing the relevance of the antibonding interactions.

Repulsion energy values become sufficiently large to destabilize hollow adsorption, particularly when a $\mathrm{Pt}$ atom and adsorbed $\mathrm{O}_{2}$ are aligned with the $z$ axis, i.e., hollow $\mathrm{Pt}(100)$ and hollow (3-3) in $\mathrm{Pt}(111)$ (Table 2, Figure 4c,h). The adsorption bond which results from bonding interactions with a $\mathrm{Pt}$ atom in the second layer is similar to that previously described for linear coordination. The most stable configuration on both Pt surfaces implies a nearly dissociated state, which can be simply described as an ionic pair with the positive end closer to the Pt surface. Together with a charge transfer from the $\mathrm{O}$ atom closer to the surface, the $\pi$ Mulliken population in the second $\mathrm{O}$ atom increases. Besides, the $\sigma$ contribution on $\mathrm{Pt}(100)$ also increases (Table 3).

On-top side-on adsorbate coordination is characterized by a large stabilization of the $\pi^{*} \mathrm{O}_{2}$ molecular orbital through bonding interaction with $\mathrm{d}_{x y} \mathrm{Pt}$ atom orbitals, as a consequence of the $\mathrm{O}_{2}$ adsorbed structure parallel to the surface (Figure 4d,i). The $\sigma$ and $\pi \mathrm{O}_{2}$ molecule bonding orbitals are also involved in this interaction, their relative weights being determined by the specific Pt surface geometry, that is, the $\mathrm{O}-\mathrm{O}$ bond length. The larger $\mathrm{O}-\mathrm{O}$ bond length in $\mathrm{Pt}(111)$ weakens the $\sigma_{\mathrm{p}}$ bond in the $\mathrm{O}_{2}$ molecule and diminishes the importance of the $\mathrm{O}_{2}-\mathrm{Pt}$ interaction as compared to $\mathrm{Pt}(100)$. Otherwise, the greater $\mathrm{O}_{2}$ bond length results from a larger $\pi^{*}$ orbital population due to a charge transfer from the most densely packed $\mathrm{Pt}(111)$ structure. This effect does not reflect in the energy level resulting from the molecular orbital interactions depicted in Figure $4 \mathrm{e}, \mathrm{j}$ for the bridge side-on geometry, as these interactions involve optimized geometries where interatomic distances are already stabilized, yielding a greater $r_{0-0}$ on $\mathrm{Pt}(111)$ resulting from the larger population of the $\pi^{*}$ orbitals. As previously discussed for hollow coordination, the $r_{0-0}$ equilibrium value for the on-top side-on adsorbate coordination almost corresponds to a dissociated $\mathrm{O}_{2}$ adsorbate, where the $\mathrm{O}$ atoms are bridge coordinated to adjacent Pt sites. Nevertheless, for equilibrium interatomic distances, the $\mathrm{O}_{2}$ molecular orbitals are still defined. Similar calculations ${ }^{22}$ without adsorbed $\mathrm{O}_{2}$ geometry optimization result in a greater contribution of $\pi_{z} \mathrm{O}_{2}$ molecular orbitals which, for a shorter $\mathrm{O}-\mathrm{O}$ interatomic distance, become closer to the $\mathrm{Pt}$ atom just below.

The stabilization of the bridge side-on geometry implies the interaction of the $\sigma$ and $\pi \mathrm{O}$ atom orbitals with d orbitals in the two closest symmetrically equivalent $\mathrm{Pt}$ atoms (Figure $4 \mathrm{e}, \mathrm{j}$ ). This $\mathrm{O}_{2}$ adsorbate configuration is characterized by the stabilization of the $\pi^{*}$ molecular orbitals of $\mathrm{O}_{2}$ with $\mathrm{d}_{z^{2}} \mathrm{Pt}$ atom orbitals. The Mulliken population analysis indicates an oxygen to metal charge transfer without back-bonding. The particular geometry of the $\mathrm{Pt}$ site facilitates the simultaneous interactions of both $\mathrm{O}$ atoms with adjacent $\mathrm{Pt}$ atoms, leading to a greater stabilization of the $\mathrm{Pt}_{\mathrm{N}} \mathrm{O}_{2}$ structure on $\mathrm{Pt}(100)$, where the charge transfer is favored because of the lower electronic density of $\mathrm{Pt}(100)$ as compared with $\mathrm{Pt}(111)$. Despite the similarity of adsorption sites, the local 



Figure 5. Total energy change (eV) of the $\mathrm{Pt}_{M} \mathrm{O}_{2}$ ensembles as a function of ro-O. (a) $[\mathrm{Pt}(111)]_{18} \mathrm{O}_{2}$, (b) $[\mathrm{Pt}(100)]_{18} \mathrm{O}_{2}$. (৫) bridge side-on, (O) bridge end-on, $(\nabla)$ on-top end-on, $(\nabla)$ hollow, $(\square)$ on-top side-on.

geometry, defined by two $\mathrm{Pt}$ atoms with $r_{\mathrm{Pt}-\mathrm{Pt}}=0.277 \mathrm{~nm}$ on both $\mathrm{Pt}(100)$ and $\mathrm{Pt}(111)$, leads to an adsorbate geometry with a greater ro-o value on $\mathrm{Pt}(111)$. The electronic characteristics of $\mathrm{Pt}(100)$ and $\mathrm{Pt}(111)$ determine specific charge-transfer contributions and the $\mathrm{O}_{2}$ molecular orbital occupation. In particular, a greater occupation of $\mathrm{O}_{2} \pi$ orbitals on $\mathrm{Pt}(111)$ favors (Table 3) larger ro-ovalues and the $\mathrm{O}_{2}$ dissociation. Again, as no real local minima can be defined, the adsorbate geometry and electronic characteristics have also been evaluated at the inflection point resulting from the energy vs $r_{\mathrm{O}} \mathrm{o}$ plot.

Summing up, data assembled in Table 2 show that the most stable $\mathrm{Pt}_{N} \mathrm{O}_{2}$ structure corresponds to bridge side-on adsorbate geometry on both $\operatorname{Pt}(111)$ and $\operatorname{Pt}(100)$, although a larger adsorbate stabilization appears on $\mathrm{Pt}(100)$. This difference results from the more efficient overlap of both $O$ atoms with the nearest neighbor $\mathrm{Pt}$ atoms on $\mathrm{Pt}(100)$. For bridge side-on coordination, the adsorption bond results from a charge transfer from $\mathrm{O}_{2}$ to the $\mathrm{Pt}$ surface and a partial back-bonding to the $\mathrm{O}_{2}-\pi^{*}$ orbital. This leads to an increase in $r_{\mathrm{O}-\mathrm{O}}$ and, then, $\mathrm{O}_{2}$ dissociation when backbonding becomes sufficiently large. Negative charge densities in $\mathrm{O}$ atoms of the adsorbed $\mathrm{O}_{2}$ molecule have occasionally been reported, ${ }^{20,22}$ especially when no full optimization was considered. Results from this work indicate that the large $\pi^{*} \mathrm{O}_{2}$ population in the $\mathrm{O}$ atoms is relaxed when the atomic overlaps are redefined after the geometry optimization routine. On the other hand, the adjustment of the equilibrium potential (VSIP) to minimize the electronegativity difference resulting from Pauling's ionicity relationship results, for this system, in a downward shift of the $\mathrm{d}$ band with the simultaneous increase in the VSIP absolute value in $\mathrm{O}$ atoms. This means a softening of the back-bonding effect.

Although no experimental data about the $\mathrm{Pt}(100) \mathrm{O}_{2}$ adsorbate geometry has been found, NEXAFS measurements of Pt(111) $\mathrm{O}_{2}{ }^{28-31}$ yielded an $r_{0-0}=0.132 \mathrm{~nm}$ and a distance of 0.175 $\mathrm{nm}$ from the adsorbed $\mathrm{O}_{2}$ to the first $\mathrm{Pt}$ atom layer. These figures agree reasonably well with those resulting from the calculations of this work (Table 2). Furthermore, $\mathrm{O}-\mathrm{O}$ vibration frequencies of peroxo compounds were detected for the same system by highresolution EELS spectra (HREELS). ${ }^{26,27}$ Likewise, from other semiempirical calculations it has been concluded that $\sigma_{d z^{2}}$ and $\sigma_{d z x}$ orbitals are the most important ones in the stabilization of the adsorption bond. ${ }^{22}$ Nevertheless, the molecular orbital analysis made in this work indicates that the interaction between the $\pi \mathrm{O}_{2}$ molecular orbitals and $\mathrm{d}_{x y} \mathrm{Pt}$ atomic orbitals also contributes to the adsorption bonds (Figure $4 \mathrm{~d}, \mathrm{e}, \mathrm{i}$ ). On the basis of the previous discussion, it has to be emphasized that not the coincidence of our results with those already known for $\mathrm{O}_{2}$ interaction with $\mathrm{Pt}(111)$ but the larger stability of the $\mathrm{O}_{2}$ molecule on $\mathrm{Pt}(100)$ toward dissociation is the main topic of this work.

3.2. Molecular vs Dissociative $\mathrm{O}_{2}$ Adsorption on Pt. Dissociation of the adsorbed $\mathrm{O}_{2}$ molecule implies the elongation of the $\mathrm{O}-\mathrm{O}$ bond until the $\mathrm{O}-\mathrm{Pt}$ interactions prevail. For the adsorption geometries presented in section 3.1 above, two different adsorbed states can be produced depending on the orientation of the $\mathrm{O}-\mathrm{O}$ bond relative to the $\mathrm{Pt}$ surface. Thus, perpendicular coordination (on-top, bridge, hollow) would result in a single $O$ atom adsorbed on the surface and the second $\mathrm{O}$ atom infinitely distant, whereas parallel coordination would lead to a final state of two $\mathrm{O}$ atoms coordinated in adjacent positions. The parallel coordination is of particular interest in this work, since $\mathrm{O}_{2}$ electroreduction first involves a simultaneous $\mathrm{H}^{+}$ion and electron transfer prior to dissociation. 6,7 The possibility of $\mathrm{O}_{2}$ dissociation depends not only on the energy difference between the initial and the final adsorbed states but also on the energy related to the geometry of the intermediates that defines the transition from one to the other.

To analyze the energy associated with the transitions for parallel coordination, roo has been varied in $0.005-\mathrm{nm}$ steps from 0.08 to $0.260 \mathrm{~nm}$, and the energy of each ensemble has been evaluated after a full coordinate optimization. The results plotted in Figure $5 a$,b show a clear stabilization of molecular $\mathrm{O}_{2}$ for bridge end-on and on-top end-on coordinations. Conversely, $\mathrm{O}_{2}$ dissociative adsorption appears to be favored for bridge side-on, on-top sideon, and hollow coordinations on both $\mathrm{Pt}(111)$ and $\mathrm{Pt}(100)$, as the real minima appear for this adsorbed state.

Let us focus our attention on bridge side-on coordination because this structure is associated with the greatest $\mathrm{Pt}_{N} \mathrm{O}_{2}$ stability and it can also explain the different trends of the $\mathrm{O}_{2}$ adsorption toward dissociation, depending on the $\mathrm{Pt}$ topology.

A clear minimum is defined for $\mathrm{Pt}(100) \mathrm{O}_{2}$ with $r_{0-O}=0.119$ $\mathrm{nm}$ and a $0.161-\mathrm{nm}$ value for the perpendicular distance of $\mathrm{O}_{2}$ to the surface ( $h$ in Table 2). Although the energy is lower $(0.61$ $\mathrm{eV}$ ) for the dissociated system, an activation energy equal to 0.56 $\mathrm{eV}$ is required for the $\mathrm{O}_{2}$ dissociation on $\mathrm{Pt}(100) \mathrm{O}_{2}$. Besides, the lowest energy value is also related to $\mathrm{O}$-a toms bonded to $\mathrm{Pt}(111)$, with no other local energy minima except for an inflection in the energy vs $r_{0-0}$ curve. Then, the adsorption of $\mathrm{O}_{2}$ on $\mathrm{Pt}(111)$ involves $\mathrm{O}_{2}$ dissociation.

The $\mathrm{O}_{2} \pi^{*}$ population is larger on $\mathrm{Pt}(111) \mathrm{O}_{2}$ than on $\mathrm{Pt}(100)$ $\mathrm{O}_{2}$ for bridge side-on coordination (Table 3 ). The filling of antibonding orbitals, which is favored on $\mathrm{Pt}(111)$, weakens the $\mathrm{O}-\mathrm{O}$ bond strength and becomes the main reason why $\mathrm{O}_{2}$ dissociative adsorption on the most densely packed $\mathrm{Pt}(111)$ surface is favored. 


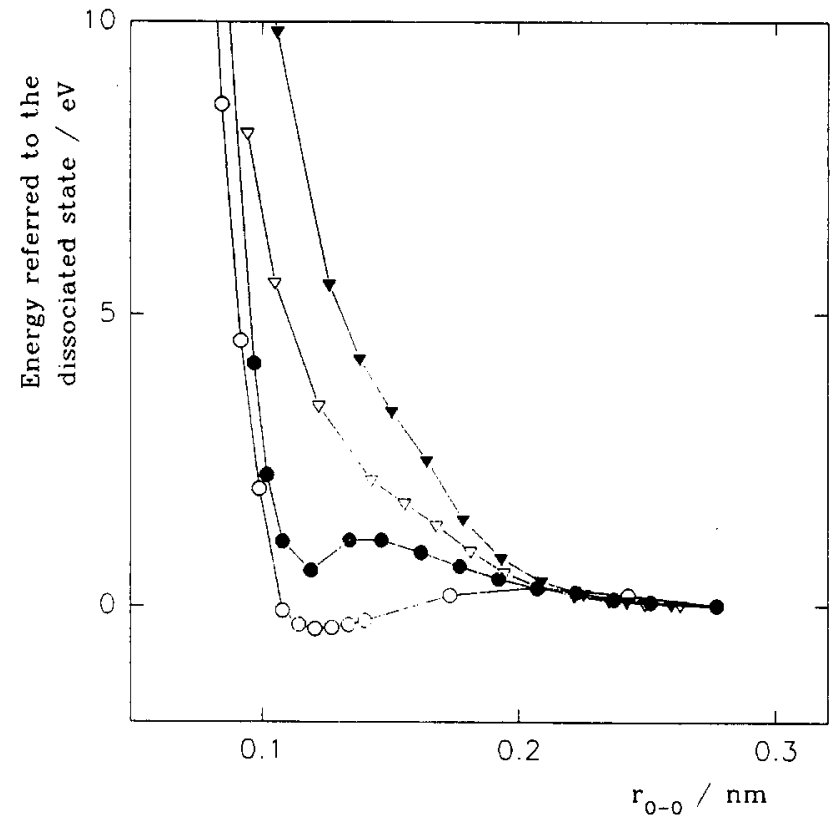

Figure 6. Applied potential dependence of the energy vs roo function for the most stable bridge side-on configuration of $[\mathrm{Pt}(100)]_{18} \mathrm{O}_{2}$. (V) $-1.4 \mathrm{eV},(\nabla)-0.8 \mathrm{eV},(\bullet) 0.0 \mathrm{eV}$, and $(0)+0.5 \mathrm{eV}$. Energy values are normalized to the dissociated state, for each applied potential.

Molecular orbital calculations allow us to conclude that the relative contribution of dissociative and molecular $\mathrm{O}_{2}$ adsorption on $\mathrm{Pt}$ is determined by the relative position of the $\mathrm{Pt} \mathrm{d}$ band with respect to $\pi^{*} \mathrm{O}_{2}$ orbital energy levels. Because the $\mathrm{Pt} d$ band position changes with the applied potential, the characteristics of the $\mathrm{O}_{2}$ adsorption become potential dependent, as it is expected for the OERR. Thus, positive potentials shift the $\mathrm{Pt} d$ band downward, decreasing the $\pi^{*} \mathrm{O}_{2}$ orbital population and favoring molecular adsorption. On the other hand, upward shifting for negatively charged $\mathrm{Pt}$ would promote dissociative $\mathrm{O}_{2}$ adsorption through the filling of the $\pi^{*}$ orbitals. The energy vs ro-o plots for bridge side-on adsorption on $\mathrm{Pt}(100)$, referred to the dissociated state at different applied potentials (Figure 6), show that no stable molecular $\mathrm{O}_{2}$ adsorption results on negatively charged surfaces, whereas positive charging results in a $\mathrm{Pt}(100) \mathrm{O}_{2}$ ensemble. Similar potential shifts applied to $\mathrm{Pt}(111)$ are insufficient to stabilize molecular $\mathrm{Pt}(111) \mathrm{O}_{2}$ adsorbate ensembles.

Hence, the influence of the applied electric potential becomes extremely important to determine the stability of $\mathrm{O}_{2}$ adsorbates on $\mathrm{Pt}(111)$ and $\mathrm{Pt}(100)$ clusters, which may appear as intermediate surface species in the OERR.

3.3. Possible Species Involved in the Mechanism of OERR on $\mathrm{Pt}(111)$ and $\mathrm{Pt}(\mathbf{1 0 0})$ Surfaces. The preceding structural stability study of $\mathrm{O}_{2}$ adsorbates on $\mathrm{Pt}$ provides the possibility of exploring further mechanistic aspects of the OERR, particularly in relation to possible species involved in the reaction, which may account for the different behavior of $\mathrm{Pt}(111)$ and $\mathrm{Pt}(100)$ electrode surfaces.

Several mechanisms have been postulated to interpret OERR kinetic data. 12,62-69 Following $\mathrm{O}_{2}$ dissociative adsorption on Pt(111), the OERR in aqueous acids would imply a possible coordination of $\mathrm{H}^{+}$ions from the solution to $\mathrm{O}$ adatoms, which further desorb as $\mathrm{H}_{2} \mathrm{O}$ at negative potentials. The fact that only $\mathrm{H}_{2} \mathrm{O}$ molecules desorb from $\mathrm{Pt}(111)$ in the course of the OERR is consistent with the dissociative $\mathrm{O}_{2}$ adsorption on this $\mathrm{Pt}$ surface. In contrast, molecular $\mathrm{O}_{2}$ adsorption would produce a peroxolike adsorbate structure on $\mathrm{Pt}(100)$ which would give rise to $\mathrm{H}_{2} \mathrm{O}_{2}$ desorption at negative potentials. Peroxo intermediates and $\mathrm{H}_{2} \mathrm{O}_{2}$ were experimentally detected mostly on $\mathrm{Pt}(100)$ electrodes. Therefore, a tentative explanation for the peroxo intermediate species formation on $\mathrm{Pt}(100)$ can be advanced.



Figure 7. Energies associated with possible steps in the $\mathrm{H}$ atom transfer from $\mathrm{OH}$ to a peroxo group on $[\mathrm{Pt}(100)]_{25} \mathrm{O}_{2} \mathrm{OH}$. The arbitrary reaction coordinate is defined as the distance between the $\mathrm{H}$ atom and the closest $O$ atom in the peroxo group. (A) Initial state: $r_{04-06}=0.123 \mathrm{~nm}, r_{\mathrm{Pt} 3-}-\mathrm{O}_{6}$ $=0.168 \mathrm{~nm}, r_{\mathrm{O} G-\mathrm{H} 7}=0.115 \mathrm{~nm}$, planar angles, $\alpha_{\mathrm{P} t 3,06, \mathrm{H} 7}=180^{\circ}, \alpha_{\mathrm{Pt} 2 \mathrm{Pt} 3, \mathrm{O}}$ $=90^{\circ}$. (B) Intermediate state: $r_{04-06}=0.147 \mathrm{~nm}, r_{\mathrm{pt3}-06}=0.182 \mathrm{~nm}$, $r_{06-\mathrm{H} 7}=0.20 \mathrm{~nm}, \alpha_{\mathrm{P} 13, \mathrm{O6}, \mathrm{H} 7}=120^{\circ}, \alpha_{\mathrm{P} 2, \mathrm{Pt} 3,06}=80^{\circ}$. (C) Final state: $r_{04-06}=0.133 \mathrm{~nm}, r_{\mathrm{P} 33-O 6}=0.162 \mathrm{~nm}, r_{O S-\mathrm{H} 7}=0.117 \mathrm{~nm}, \alpha_{\mathrm{P} 73,05, \mathrm{H} 7}=$ $151^{\circ}, \alpha_{\mathrm{P} 22, \mathrm{P} 23,06}=90^{\circ}$

As discussed in section 3.2, peroxo $\mathrm{O}_{2}$ adsorbates (bridge sideon coordination) would dissociate as the applied potential is shifted negatively (Figure 6) leading to $\mathrm{H}_{2} \mathrm{O}$ as the final product as it was also found in $\mathrm{Pt}(111)$. However, it should be borne in mind that at potentials where $\mathrm{O}_{2}$ adsorption on $\mathrm{Pt}$ occurs, other species resulting from the $\mathrm{H}_{2} \mathrm{O}$ electrochemical and chemical decomposition, such as $\mathrm{OH}$ and $\mathrm{O}$ adatoms, would also participate in the adsorbate structure, yielding, for instance, a $[\mathrm{Pt}(100)]_{N} \mathrm{O}_{2}$ $\mathrm{OH}$ ensemble at the equilibrium potential.

Following the same theoretical procedure, the geometry of the $[\mathrm{Pt}(100)]_{N} \mathrm{O}_{2} \mathrm{OH}$ ensemble was fully optimized for both the $\mathrm{O}_{2}$ and $\mathrm{OH}$ adsorbates. The adsorption of $\mathrm{OH}$ results in a linear (on-top) configuration adjacent to the peroxo-group bridge sideon adsorbed species, rendering a structure that is 0.84 and 2.04 $\mathrm{eV}$ more stable than those associated with an $\mathrm{OH}$ bridge and an $\mathrm{OH}$ hollow coordination, respectively. Stability calculations of these ensembles showed that a $\mathrm{H}$ atom transfer from the hydroxo to the peroxo group is favored. This $\mathrm{H}$ atom transfer implies an initial tilting of the $\mathrm{Pt}-\mathrm{O}-\mathrm{H}$ bond until it becomes parallel to the $\mathrm{Pt}-\mathrm{O}$ bond in the peroxo group, with a simultaneous elongation of the $\mathrm{Pt}-\mathrm{O}$ bond from 0.168 to $0.182 \mathrm{~nm}$. Besides, the energy increases slightly while the $\mathrm{OH}$ bond is bent toward the peroxo group to be finally transferred with a net gain of $0.41 \mathrm{eV}$ in stability (Figure 7). Then, in the OERR potential range, the $H$ atom transfer takes place and the adsorbate ensemble can be better described as a hydrogenated peroxo group plus an $\mathrm{O}$ atom coadsorbed on $\mathrm{Pt}(100)$. The geometry of this adsorbed ensemble, a possible reaction intermediate in the OERR on $\mathrm{Pt}(100)$, has also been fully optimized in bond lengths and angles, as it is shown in Figure 8.

The $\mathrm{H}$ atom transfer implies an activation energy equal to 0.26 $\mathrm{eV}$ (Figure 7). We are aware that the level of these calculations does not allow us to infer that the proposed intermediate is the one that has the lowest energy. Accordingly, a lower activation energy barrier should not be precluded. The energy required for the $\mathrm{Pt}(100) \mathrm{O}_{2} \mathrm{OH}$ to $\mathrm{Pt}(100) \mathrm{O}_{2} \mathrm{HO}$ transition might be provided by other simultaneous reactions, such as the underpotential deposition, upd, $\mathrm{H}_{2} \mathrm{O}$ discharge, or the $\mathrm{O}_{2}$ adsorption on $\mathrm{Pt}$.

The stability of the $\mathrm{O}_{2} \mathrm{H}-\mathrm{O}$ coadsorbate on $\mathrm{Pt}(100)$ was also calculated as a function of the applied potential. Changes in the 


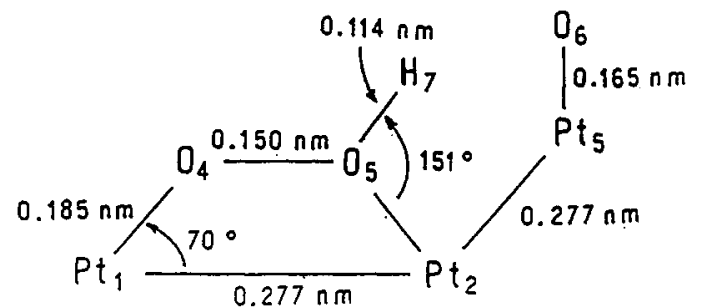

Figure 8. Geometric parameters of the fully optimized adsorbed ensemble structure, resulting from $[\mathrm{Pt}(100)]_{25} \mathrm{O}_{2} \mathrm{OH}$, after the $\mathrm{H}$ atom transfer from $\mathrm{OH}$ to a peroxo group.

TABLE 4: Charges on Pt and $\mathrm{O}_{2}\left(q_{\mathrm{Pt}}\right.$ and $\left.q_{\mathrm{o}}\right)$ and Mulliken Overlap Populations $\left(c_{i}\right)$ for Relevant Bonds at the $[\mathrm{Pt}(100)]_{25} \mathrm{O}_{2} \mathrm{OH}$ Ensemble at Different Potentials $(E)$

\begin{tabular}{|c|c|c|c|c|c|}
\hline & \multicolumn{5}{|c|}{$E(\mathrm{eV})$} \\
\hline & 0.0 & -0.40 & -0.80 & -1.00 & -1.40 \\
\hline$q_{\mathrm{P}+1}(\mathrm{eu})$ & 1.4215 & 1.3536 & 1.3382 & 1.3372 & 1.2926 \\
\hline$q_{\mathrm{Pt} 2}(\mathrm{eu})$ & 1.3980 & 1.3620 & 1.3425 & 1.3176 & 1.3174 \\
\hline$q_{\mathrm{Pt3}}(\mathrm{eu})$ & 2.1640 & 2.3447 & 2.3281 & 2.2463 & 2.0765 \\
\hline 904 (eu) & 0.6435 & 0.0125 & -0.2663 & -0.3754 & -0.5477 \\
\hline $905(\mathrm{eu})$ & 1.0642 & 0.6393 & 0.4077 & 0.3224 & 0.1854 \\
\hline 906 (eu) & 0.6435 & 0.2380 & -0.2964 & -0.5522 & -0.9173 \\
\hline$q_{\mathrm{H} 7}(\mathrm{eu})$ & 0.2226 & 0.2107 & 0.2004 & 0.1956 & 0.1879 \\
\hline$c_{P(1-O 4}$ & 0.7447 & 0.6731 & 0.6006 & 0.6335 & 0.6108 \\
\hline$c_{\mathrm{P}_{2} 2-\mathrm{O}}$ & 0.6705 & 0.6313 & 0.5440 & 0.6038 & 0.5882 \\
\hline CO4-OS & 0.3563 & 0.3084 & 0.3226 & 0.2739 & 0.2496 \\
\hline $\cos -\mathrm{H}_{7}$ & 0.4647 & 0.4691 & 0.5507 & 0.4741 & 0.4764 \\
\hline$C_{P+3-06}$ & 1.2255 & 1.1814 & 0.6501 & 0.9994 & 0.8771 \\
\hline
\end{tabular}

adsorbed structure due to the upward shifting of the $\mathrm{d}$ band, i.e., potential negatively increased, have been studied, after a full optimization of the geometry for each set of the defined conditions. Thus, the activation energy barrier for the $\mathrm{H}$ atom displacement from oxygen 6 to oxygen 5 (Figure 8) depends on the potential, and it decreases almost to zero for $\mathrm{a}-1 \mathrm{eV}$ potential assisting the OERR in the forward direction. Accordingly, it is reasonable to admit that the larger the cathodic overpotential the lower the activation energy.

Changes in the Mulliken atomic overlaps with the applied potential (Table 4) show that, although they both decrease for negative potentials, the destabilization of the $\mathrm{Pt}-\mathrm{O}$ bond becomes more pronounced than that of the $\mathrm{O}-\mathrm{O}$ bond for a given potential change. Hence, although a competition between the dissociation of the peroxo adsorbate and the formation of a hydroperoxo intermediate ensemble takes place, it is likely that the hydroperoxo intermediate ensemble preferentially desorbs as $\mathrm{H}_{2} \mathrm{O}_{2}$ prior to dissociation. On the other hand, negative applied potentials stabilize the large negative charge density in the $O$ atom at the peroxo group not bonded to $\mathrm{H}$ atom (oxygen 4 in Figure 8) which becomes a center for the $\mathrm{H}^{+}$ion coordination, followed by $\mathrm{H}_{2} \mathrm{O}_{2}$ desorptive formation.

The hydroperoxide formation on $\mathrm{Pt}(100)$ implies that at negative potentials, the remaining oxo species (Figure 7) would be negatively charged (Table 4) and, after the $\mathrm{H}^{+}$ion coordination, $\mathrm{H}_{2} \mathrm{O}$ desorption would occur. The mechanism for this reaction is similar to that proposed on $\mathrm{Pt}(111)$, and it justifies the simultaneous desorption of $\mathrm{H}_{2} \mathrm{O}$ from $\mathrm{Pt}(100)$ and the detection of $\mathrm{H}_{2} \mathrm{O}$ as the only OERR product on $\mathrm{Pt}(111)$.

\section{Conclusions}

The interaction of a single $\mathrm{O}_{2}$ molecule on $\mathrm{Pt}(111)$ and $\mathrm{Pt}$ (100) structures was studied. On both surfaces, bridge side-on is the most stable coordination geometry for $\mathrm{Pt}_{N} \mathrm{O}_{2}$. However, a dissociative $\mathrm{O}_{2}$ interaction on $\mathrm{Pt}(111)$ and a molecular $\mathrm{O}_{2}$ interaction on $\mathrm{Pt}(100)$ are favored. The different characteristics of the $\mathrm{O}_{2}$ adsorption on both surfaces are reflected in the OERR, leading to the preferential desorption of $\mathrm{H}_{2} \mathrm{O}$ from $\mathrm{Pt}(111)$ and $\mathrm{H}_{2} \mathrm{O}_{2}$ from $\mathrm{Pt}(100)$.
$\mathrm{H}_{2} \mathrm{O}$ desorption results from the coordination of $\mathrm{H}^{+}$ions from the media to $\mathrm{O}$ adatoms in the adsorbate ensemble, which become negatively charged for negative applied potentials due to the upward shift of the $\mathrm{Pt} d$ band. On the other hand, $\mathrm{H}_{2} \mathrm{O}_{2}$ results from the coordination of an $\mathrm{H}^{+}$ion to peroxo intermediates adsorbed on $\mathrm{Pt}(100)$, which are more likely to desorb than to dissociate, according to the larger decrease in the $\mathrm{Pt}-\mathrm{O}$ than the $\mathrm{O}-\mathrm{O}$ overlaps, at negative potentials.

Results from this quantum chemical approach justify the detection of peroxo and oxo intermediates on $\mathrm{Pt}(100)$ structures in the course of the OERR, rather than the structure of the oxo intermediates on $\mathrm{Pt}(111)$.

Acknowledgment. This work was financially supported by the Consejo Nacional de Investigaciones Científicas y Técnicas (CONICET) and Fundación Antorchas of Argentina. C.F.Z. thanks the Universidad de la República, Montevideo (Uruguay), for the fellowship granted.

\section{References and Notes}

(1) Tarasevich, M. R.; Sadkowski, A.; Yeager, E. B. Oxygen Electrochemistry. In Comprehensive Treatise of Electrochemistry, Vol. 7: Kinetics and Mechanisms of Electrode Processes; Conway, B. E., Bockris, J. O'M. Yeager, E. B., Kahn, S., White, R. W., Eds.; Plenum Press: New York, 1983; Chapter 6, pp 301-398.

(2) Hoare, J. P. The Electrochemistry of Oxygen; J. Wiley and Sons: New York, 1968.

(3) Appleby, A. J. In Modern Aspects of Electrochemistry; Bockris, J. O’M., Conway, B. E., Eds.; Plenum Press: New York, 1974; Vol. 9, Chapter

(4) Damjanovic, A.; Brusic, V. Electrochim. Acta 1967, 12, 615. $126,736$.

(6) Yeager, E. B. Electrochim. Acta 1984, 29, 1527

(7) Zinola, C. F.; Castro Luna, A. M.; Triaca, W. E.; Arvia, A. J. J. Appl. Electrochem. 1994, 24, 119.

(8) El Kadiri, F.; Faure, R.; Durand, R. J. Electroanal. Chem. 1991, 301,777 .

(9) Zinola, C. F.; Castro Luna, A. M.; Triaca, W. E.; Arvia, A. J. J. Appl. Electrochem., in press.

(10) (a) Appleby, A. J. J. Electroanal. Chem. 1970, 24, 97. (b) Parthasarathy, A.; Srinivasan, S.; Appleby, J.; Martin, C. R. J. Electroanal. Chem. 1992, 339, 101. (c) Parthasarathy, A.; Srinivasan, S.; Appleby, J.; Martin, C. R. J. Electrochem. Soc, 1992, 139, 2856. (d) Parthasarathy, A.; Srinivasan, S.; Appleby, J.; Martin, C. R. J. Electrochem. Soc. 1991, 138 , 916.

(11) Hsueh, K.-L.; González, E.;Srinivasan, S.;Chin, D.-T. J.Electrochem. Soc. 1984, 131, 822.

(12) Damjanovic, A.; Genshaw, M. A.; Bockris, J. O'M. J. Chem. Phys. $1964,45,4057$.

(13) Ross, P. N.; Andriacos, P. C. J. Electroanal. Chem. 1983, 154, 205.

(14) Glass, J. T.; Cahen, G. L., Jr.; Stoner, G. E. J. Electrochem. Soc. $1989,136,656$

(15) Guo, X.-C.; Bradley, J. M.; Hopkins, A.; King, D. A.; Surf. Sci. Lett. 1993, 292, L786.

(16) Poehlmann, E.; Schmitt, M.; Hoinkes, H.; Wilsch, H. Surf. Sci. 1993, $291,317$.

(17) de Meijere, A.; Hiriyama, H.; Hasselbrink, E. Phys. Rev. Lett. 1993, 70,1147 .

(18) Ohno, Y.; Matsushima, T.; Tanaka, S.; Yagasaki, E.; Kamada, M. Surf. Sci. 1992, 275, 281.

(19) Benesh, G. A.; Lingane, L. S. G. Surf. Sci. 1992, 261, 207.

(20) Hellsing, B. Surf. Sci. 1993, 282, 216.

(21) Nakatsuji, H.; Nakai, H. J. Chem. Phys. 1993, 98, 2423.

(22) Chan, A. W. E.; Hoffmann, R.; Ho, W. Langmuir 1992, 8, 1111.

(23) Panas, I.; Sieghbahn, P. Chem. Phys. Lett. 1988, 88, 458.

(24) Selmani, A.; Andzelm, J.; Salahub, D. R. Int. J. Quantum Chem. 1986, 29,829 .

(25) Barteau, M. A.; Ko, E. I.; Maddix, R. J. Surf. Sci. 1981, 102, 99.

(26) Steininger, H.; Lehwald, S.; Ibach, H. Surf. Sci. 1982, 123, 1.

(27) Vaska, L. Acc. Chem. Res. 1976, 9, 175.

(28) Outka, D. A.; Stöhr, J.; Jark, W. Phys. Rev. B 1987, 35, 4119

(29) Wurth, W.; Stöhr, J.; Feulner, P.; Pan, X.; Bauchspiess, K. R.; Baba,

Y.; Hudel, E.; Rocker, G.; Mentzel, D. Phys. Rev. Lett. 1990, 65, 2426.

(30) Stöhr, J.; Gland, J. L.; Eberhardt, W.; Outka, D.; Madix, R. J.; Sette, F.; Koestner, R. J.; Doebler, U. Phys. Rev. Lett. 1983, 51, 2414.

(31) Sexton, B.; Madix, R. J. Chem. Phys. Lett. 1980, 76, 294.

(32) Gland, J. L.; Sexton, B.; Fisher, G. B. Surf. Sci. 1980, 95, 587.

(33) Nakatsuji, H.; Nakai, H.;Hada, M. Metal-Ligand Interactions: from Atoms, to Clusters, to Surfaces; Salahub, D. R., Russo, N., Eds.; Kluwer Academic Publishers: Dordrecht, 1992; pp 251-285.

(34) Przybylski, K.; Koutecky, J.; Bonacic-Koutecky, V.; Schleyer, P. v. R.; Guest, M. F. J. Chem. Phys. 1991, 94, 5533. 
(35) Goursot, A.; Papai, I.; Salahub, D. R. J. Am. Chem. Soc. 1992, 114, 7452.

(36) Bagus, P. S.; Pacchioni, G. Surf. Sci. 1990, 236, 233.

(37) Hoffmann, R. J. Chem. Phys. 1963, 39, 1397.

(38) Anderson, A. B.; Hoffmann, R. J. Phys. Chem. 1974, 60, 4271.

(39) Anderson, A. B. J. Phys. Chem. 1975, 62, 1187.

(40) (a) Head, J. D.; Zerner, M. C. Chem. Phys. Lett. 1985, 122, 264. (b)

Head, J. D.; Zerner, M. C. Chem. Phys. Lett. 1986, 131, 359.

(41) Anders, L. W.; Hansen, R. S.; Bartell, L. S. J. Chem. Phys. 1973, $59,5277$.

(42) Calzaferri, G.; Forss, L.; Kamber, I. J. Phys. Chem. 1989, 93, 5366.

(43) Savary, F.; Weber, J.; Calzaferri, G. J. Phys. Chem. 1993, 97, 3722. 917.

(45) Amouyal, E.; Mouallem-Bahout, M.; Calzaferri, G. J. Chem. Phys. $1991,95,7641$.

46) Brãndle, M.; Calzaferri, G. Helv. Chim. Acto 1993, 76, 924

(47) (a) Vázquez, L.; Gómez Rodríguez, J. M.; Gómez Herrero, J.; Baró, A. M.; García, N.; Canullo, J. C.; Arvia, A. J. Surf. Sci. 1987, 181, 98. (b) Gómez, J.; Vázquez, L.; Baro, A. M.; García, N.; Perdriell, C. L.; Triaca, W. E.; Arvia, A. J. Nature 1986, 323, 612. (c) Cerviffo, R. M.; Arvia; A. J.; Vielstich, W. E. Surf. Sci. 1985, 154, 623.

(48) Tarasevich, M. R. Elektrokhimiya 1973, 9, 599.

(49) Vilinskaya, V.S.; Tarasevich, M. R. Elektrokhimiya 1973, 8, 1187.

(50) Villambi, N. R. K.; Taylor, E. J. Electrochim. Acta 1989, 34, 1449.

(51) Park, S.-M.; Ho, S.; Aruliah, S.; Weber, M. F.; Ward, C. A.; Venter,

R. D.; Srinivasan, S. J. Electrochem. Soc. 1986, 133, 1641.

(52) Anastasijevic, N. A.; Vesovic, V.; Adzic, R. R.J. Electroanal. Chem. 1987, 229, 305.

(53) Pauling, L. The Nature of the Chemical Bond, 3rd ed.; Cornell University Press: Ithaca, NY, 1992, p 45.
(54) Calzaferri, G.; Brãndle, M. QCMP 116. QCPE Bull 1992, I2, No. 4.

(55) Estiú, G. L.; Maluendes, S. A.; Castro, E. A.; Arvia, A. J. J. Electroanal. Chem. 1990, 284, 289.

(56) Estí, G. L.; Maluendes, S. A.; Castro, E. A.; Arvia, A. J. J. Phys. Chem. 1988, 92, 2512.

(57) Lide, D. R., Ed. CRC Handbook of Chemistry and Physics; CRC Press: Boca Raton, FL, 1990-91.

(58) Levine, I. N. Quantum Chemistry; Editorial A.C.: Madrid, 1977.

(59) Taube, H. J. Gen. Phys. 1965, 49, 29.

(60) Greenwood, N. N.; Earnshaw, A. In Chemistry of the Elements; Pergamon Press: Oxford, 1984.

(61) Calzaferri, G.; Marcolli, C. To be published.

(62) Anastasijevic, N. A.; Vesovic, V.; Adzic, R. R. J. Electroanal. Chem. $1987,229,317$.

(63) Zurilla, R. W.; Yeager, E. B. Technical Report No. 23, Case Western University, 1969.

(64) Wroblowa, H.S.; Pan, Y-Chi; Razumney, G. J. Electroanal. Chem. $1976,69,195$.

(65) Bagotskii, V.S.; Tarasevich, M. R.; Filinovskii, V. Yo; Elektrokhimiya $1969,5,1218$.

(66) Bagotskii, V.S.; Tarasevich, M.R.; Filinovskii, V.Yo; Elektrokhimiya $1972,6,84$.

(67) Hsueh, K. L.; Chin, D. T.; Srinivasan, S. J. Electroanal. Chem. 1983, 153,79 .

(68) O'Grady, W. E.; Taylor, E. J.; Srinivasan, S. J. Electroanal. Chem. $1982,132,137$. 1036. 